Kennesaw State University

DigitalCommons@Kennesaw State University

Faculty Publications

$11-1994$

\title{
Using Portfolio Reflections to Re-Form Instructional Programs and Build Curriculum
}

Sarah Robbins

Kennesaw State University, srobbins@kennesaw.edu

Nancy Brandt

The Valley School

Susan Goering

Flint Community Schools, Flint MI

Jeanette Nassif

Flint Central High School, Flint MI

Kathleen Wascha

The Valley School

Follow this and additional works at: https://digitalcommons.kennesaw.edu/facpubs

Part of the Creative Writing Commons, and the Curriculum and Instruction Commons

\section{Recommended Citation}

Robbins, S., Brandt, N., Goering, S., Nassif, J., \& Wascha, K. (1994). Using portfolio reflections to re-form instructional programs and build curriculum. English Journal, 83(7), 71.

This Article is brought to you for free and open access by DigitalCommons@Kennesaw State University. It has been accepted for inclusion in Faculty Publications by an authorized administrator of DigitalCommons@Kennesaw State University. For more information, please contact 


\section{Using Portfolio Reflections to Re-form Instructional Programs and Build Curriculum}

Sarah Robbins, Nancy Brandt, Susan Goering, Jeanette Nassif, and Kathleen Wascha

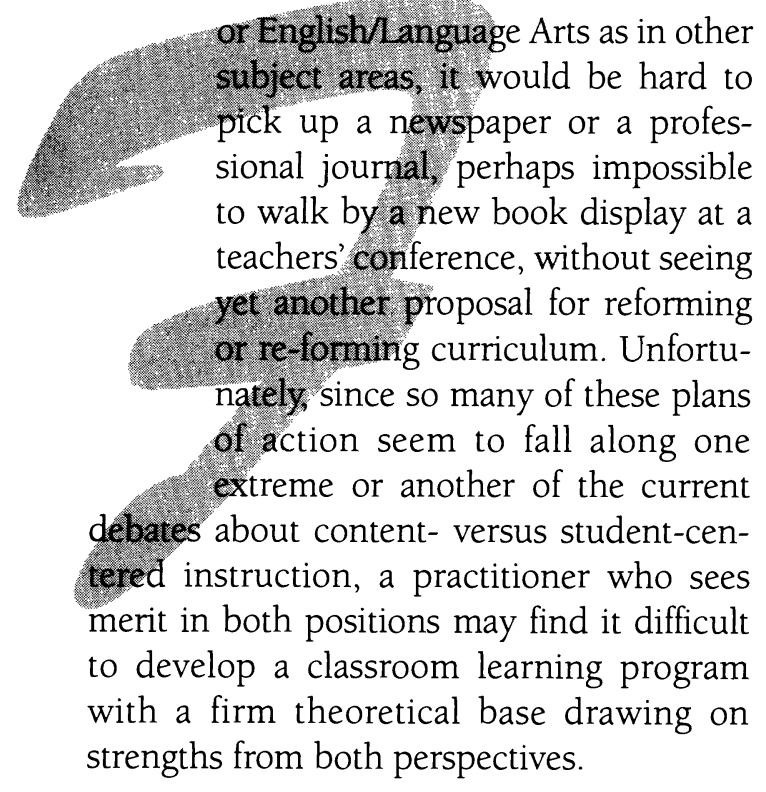

\section{TWO VISIONS OF CURRICULUM}

On the one hand, at its most reductive extreme, some of the insistent and persuasive advocates of a traditional English curriculum ally themselves with keepers of cultural literacy by arguing the need to insure common content elements (e.g., particular "Great Books" texts by "major" authors) and consistent skills instruction (as measured, frequently, in standardized instruments). In practice, teachers allied with this perspective might be drawing on specific district-level guidelines for what materials to include in a literature syllabus, delivering daily instruction focused on a textbook's pre-made materials and activities, attending to public cries for "back to basics" vocabulary instruction through generating weekly lists and tests, or creating writing assignments to mirror specific assessment prompts they expect their students to encounter on a state writing assessment. In any of these cases, teachers responding to such forces in their instructional decision-making are acknowledging the role authority figures situated outside the classroom itself play in determining curricula (see, for instance, Hirsch). When the learning in particular classrooms is directed mainly by such external authorities, history (on several levels) is a key element helping to shape it.

For example, the specific district's or school building's past decisions about how courses should be conceived (e.g., classes integrating language arts versus separate courses like "Expository Writing" or "Reading" ) can sometimes carry a kind of residual force, promoting stability and discouraging innovation. Similarly, an instructor's own past learning experiences can lead her to choose the most familiar selections from the class anthology, pull tried-and-true worksheets from the file drawer, or re-use successful units without considering whether or not they fit a different group of students' unique needs. For teachers and students in such classrooms, curriculum tends to be conceived of as a predetermined collection of information and skills which students set out to acquire through a kind of orchestrated instruction. Such an approach to curriculum-building allows for original interpretation, certainly. But it is essentially dependent on students carrying out teacher/conductor-directed practice of a "prewritten text" the teacher anticipates and shapes first in her own head. This is based on what has previously been generated and regulated by great masters more than by the student players engaged in the specific learning "performance."

On the other hand, supporters of student-centered instruction tend to depict curriculum as individualized and forwardlooking, created mainly out of the aspirations of particular learners. Advocates of this perspective would stress a conception of the teacher as guiding instruction from the side rather than performing on a classroom stage, and would call for the individual students to generate their own reading and writing agendas, looking to their diverse futures rather than remaining mired in old systems
In two very

different

schools, the authors used portfolio responses to re-form the content of their classes. 
constructed for past generations. In idealized versions of this model of learner-centered teaching, students write their own curricular texts, and teachers take on more of a coach/facilitator role. Refiguring our earlier musical performance metaphor, then, we might imagine each student as a unique artist creating an original score, with the teacher providing encouragement, guid-

The NCTE/ IRA SPELA project seems to have been conceived in part to un-do this false dichotomy

between contentcentered and studentcentered curriculummaking in the English/ Language Arts classroom. ance, and support based in part on her own past music-making, in part on her sense of the student-composer's individual needs and talents. In practice, however, this model can sometimes be difficult to carry out, especially in classrooms with larger enrollments and/or curriculum coverage mandates generated from outside the particular learning site.

In addition, this model has sometimes suffered in implementation from moves to oversimplify it. We have talked with many classroom teachers who, in seeking to "do" a Nancie Atwell or a Linda Rief reading/writing workshop, have struggled so mightily to create a space where every student could become an empowered decision-maker that they missed the parts of Atwell's and Rief's philosophies which emphasize some common core experiences, knowledge, skills, and goals that everyone in their classrooms strives to attain. They may fail to acknowledge, for example, the connecting links such learner-centered classrooms strive to make in a whole-class curriculum for building among readers what Atwell calls a "literate environment" (1991, 228).

Similarly, in resisting standardization, they may focus so much on the individualization and diversity themes stressed in such classroom stories that they under-emphasize equally important unifying elements, like the "ongoing structures" which Lucy Calkins highlights in her depiction of effective writing workshops (1986, 181).

\section{STANDARDS AND CURRICULAR REFORM}

The NCTE/IRA SPELA project seems to have been conceived in part to un-do this false dichotomy between content-centered and student-centered curriculum-making in the English/Language Arts classroom. Drawing its principles from the diversity of realworld classrooms, the project worked from the start to ground its guidelines for what students should be able to know and do in an ongoing, critical examination of actual classroom practices from a wide variety of sites. These and other moves in our profession toward building living theory from examination of informed practice may, in the long run, produce guidelines which will then help reshape and re-form those very practices.

Even now, individual teachers are often building curriculum for their own classrooms based on their own interactive models of theory-making practice and practiceremaking theory. Our own particular teacher research group, made up of practitioners who have been working together for several years on the Flint Portfolio Project, has been working to develop and articulate an approach to curricular reform that allows us to critique instructional principles and practices across very different school sites while also honoring the diversity we affirm in students' needs and teachers' methods.

For high school settings, and especially for sites with a history of valuing the traditions associated with a humanities-based literature program, we have come to believe through our work with portfolio-supported reading and writing instruction that neither the content-centered nor the student-centered curriculum models described above can be fully adequate. For several years, we have been engaged-along with our students at several very different schools-in a collaborative composing process shaping an alternative model for ongoing curricular reform. Closely tied to our context-specific implementation of portfolio instruction and assessment, we have come to see curriculum itself as a text constantly being "written" by multiple authors. In our classrooms, we believe the process of "writing" that text of ongoing curriculum reformation is most easily carried out (i.e., inscribed, contested, and represented) in shared portfolio reflections composed by teachers, students, and parents.

\section{HISTORY OF A COLLABORATIVE PORTFOLIO PROJECT}

Our work together on the Flint Portfolio Project began as an experimental, bottomup enterprise in 1991-92 in two pilot classrooms, where teachers Susan Goering and Kathy Wascha decided to try out portfolios in their literature-based high school English courses. Working with support teacher-researcher Sarah Robbins, Susan and Kathy 
developed two very different applications of portfolio assessment, each tailored to the needs of their particular schools, courses, and student populations at Flint Central High School and The Valley School, respectively. Both teachers asked students to maintain folders with a wide variety of informal and formal writing assignments connected to their literature-reading. Both assessed those writings only with written and oral comments in the early stages, then later gave students the responsibility for selecting some of those pieces to revise for inclusion in a portfolio to be graded in the more traditional sense at each term's end.

However, despite the fact that the two teachers and their respective English departments both placed a high value on attentive study of literary texts, Central's identity as a large public Humanities Magnet School, drawing students from three other areas, was far different from Valley's institutional personality as a twenty-year-old, small, private $\mathrm{K}-12$ school founded in part to provide a more liberal curriculum than the city system's. Thus, though Kathy's students revised endings for Ibsen's A Doll's House and their personal satires responding to eighteenthcentury models had their counterparts in Susan's writers' Beowulf raps and Canterbury Tales-like stories, the portfolios from these classrooms, by year's end, also mirrored some key distinctions between the two classrooms' curricular contexts that showed up again when Nancy Brandt (Valley) and Jeanette Nassif (Central) joined the project in its second year.

For instance, with smaller class sizes (about 15-18) but more daily preparations (as many as six), at Valley Kathy and Nancy encouraged greater individualization in student reading and writing tasks, established "peer reader pairs" for editing rather than groups of four or five, and welcomed students' requests to insert non-school-based writing samples into the portfolio process. Meanwhile, with a much larger class size of students coming from several different home schools to participate in the magnet $\mathrm{Hu}-$ manities program at Central, Susan and Jeanette emphasized learning activities building a sense of community (e.g., small group editing rather than student-teacher conferences or edit pairs, as well as common assignments tied very closely to whole-class readings).

Despite such clear differences in the ways portfolio instruction has evolved in these two distinctive sites, one element crucial to both settings has been the emphasis all participating teachers have placed upon reflection. In fact, student reflective writing-ranging from brief list-like notes for their teacher-reader to more explicitly sought directions for how best to proceed to a new instructional step-has guided our implementation of portfolio instruction and assessment from the beginning of our project.

\section{Using Student Reflections to Direct Portfolio Implementation}

Because our portfolio program has been bottom-up and site-specific, we did not begin by choosing any specific models to follow. Instead we started with some basic beliefs about reading and writing as interactive processes and about evaluation as needing to be closely integrated with learning. Then we tried to develop strategies for portfolio construction that would be closely tied to our instructional programs. And we have continually invited the input of the particular student groups we are trying to serve as we refine our approach each year. While much of that guidance has come in the form of informal class discussion and individual, unsolicited comments made by students, from the very beginning of the project we have sought explicit ways to involve learners, through their writing, in the ongoing development, critique, and revision of the portfolio program.

At Central, for example, students are often asked to write reflections during class about the process of doing particular writing assignments. In recalling the difficulties they had carrying out a writing task, or in outlining their own questions about a text and their perceptions of its strengths and weaknesses before handing it in for peer editing, students gain valuable practice in reflectively critiquing their own writing (practice that later helps them write fuller, more formal reflective essays to introduce their portfolios).

But these informal, reflective freewrites also provide us with a much clearer understanding of the evolving curriculum for the whole classroom. In other words, by show- 
ing us what and how kids think about their own writing, these texts guide many of our decisions about teaching strategies to use in the classroom.

For instance, on the first day of the pilot semester at Central, we asked students to produce an in-class freewrite listing some of their most vivid memories of writing experiences, then developing one of those memories into a short narrative. Reading the class set later allowed us to note recurring themes (e.g., student beliefs, attitudes, and concerns) we would need to be attentive to as we structured the specific instructional strategies of our program. One of these themes was a clear concern about privacyexpressed in several students' memories of their diaries being invaded by a sibling, or of having to share a paper in class when they wanted to keep it private. Since that recurring worry had its counterpart in student reflections about how important chances to share their work with a public audience had been, we realized that our portfolio implementation program would need to provide our students with chances to make their writing public via such approaches as peer reading groups and class publications, but would also need to include safeguards for students who wanted to choose to keep individual texts private.

Once we realized that such informal, inclass reflections could help us have a better sense of how our portfolio-connected instructional changes were working for students, we began to solicit more jottings more frequently.

Students' ideas and feelings about the learning environment have continued to shape our curricular decisions, especially in the sense that, when we explicitly describe decisions we are making as being in response to student writing and when we anonymously share particular student suggestions with the class to tap their reaction, kids develop a high level of trust in us and in the portfolio process as responsive to their individual learning needs.

Thus, when we noted a relatively high degree of anxiety expressed in jottings written just after students received their second papers back in the pilot semester, we realized that simply withholding grades from early drafts and concentrating on constructive comments would not, in and of itself, relieve student fears about writing assessment. So we worked harder at making our formative evaluative comments more specific and constructive. We also had a class discussion about how it felt to work hard on a paper, then have it returned with, as one worried sophomore observed, "just comments and no grade" (the perhaps equally frustrating reverse, we all noted, of finding only a score with no justification). We gave students the option on their next draft of receiving a traditional grade if they wanted to see how they were doing in more traditional terms, and a few wrote the agreedupon request at the top of their papers calling for "letter grade, please." Most, however, seemed to have worked through their anxieties in the trust-building class discussion growing out of the students' informal writing.

Having begun to realize how important affective factors would probably be in implementing portfolios with a different group of students each year, in the second year of the project, we sometimes asked kids to write "anticipation thoughts" just before they received their first few papers back from us, so that we could better understand how they were feeling about our shift from teacher-asred-pen-wielder to teacher-as-collegialreader on initial drafts, and whether (in fact) they were truly sensing a difference in our evaluative stance.

On a more practical decision-making level, we have used informal student reflective freewrites as part of the decision-making process for selecting and refining particular instructional strategies associated with portfolio construction. Thus, student reflections guided us in establishing procedures for peer editing, deciding how many pieces should be required in a given term's portfolio, and creating a variety of scoring rubrics to reflect course goals and content.

At Valley, for example, we asked students to write about and then discuss with us the issue of how their first portfolios should be conceptualized-as records of their strongest pieces for the semester, representations of their growth over that same time period, or some combination of the above. The freewrites and ensuing debate in one class were so rich that we ended up allowing individual students to make their own choices about whether to have a "best 
works" or a developmental portfolio, and asking that they include a rationale for that choice in their reflective essay introducing the portfolio.

Meanwhile, at Central, student reflections written during the writing process for various specific assignments have helped reshape the way we gave directions and provided practice opportunities for new skills. More specifically, when their freewrites indicated that kids were having problems understanding how to implement the story-within-a story structure we had asked them to use for a narrative based on The Canterbury Tales, we wrote our own brief sample text and shared it with the class. On occasion, texts we would read while circulating through the room during small-group editing activities would lead us to stop that activity a few minutes before class ended in order to provide a mini-lesson on some concept or skill our spot-evaluating had shown to need attention.

\section{Teacher-Student Suggestions about Curriculum in Portfolio Reflections}

Over time, we noticed and increasingly sought to encourage our students' wishes to use their individual writings to re-write their shared curriculum. (This trend has been especially notable at Valley, where the institution's focus on individualized instruction is most philosophically compatible with a single student's power to reshape course content, goals, and objectives.)

At term's end, when they make choices (within a guiding framework) about what to place in the portfolios their teachers will soon evaluate, students in the Flint Portfolio Project write a reflective introduction to their selections. In our first year, we simply asked them to welcome readers to their collection, justify their choices for inclusion, and critique their own work. Teachers in our classroom research team frequently write their own informal, personal assessments of how the project is evolving in their classrooms-what changes they have seen in themselves as teachers, in their students, and in their curriculum. In one of these brief analysis papers, Kathy described how she began to see a pattern emerging in the student reflective essays from her room. The kids' reflections during the first year "dealt mainly with their assessment of their own writing," Kathy explained in her informal self-assessment. Still, when re-reading sample collections, she "began to notice" that the kids would sometimes "interject comments that were indirectly addressing other issues." Thus, Kathy saw, an individual student's comments about his "least favorite piece" might include an observation hypothesizing that his writing was weaker there because of his having "had difficulty getting into the novel," so that he "therefore had trouble organizing ... thoughts" for his writing.

Once Kathy recognized from re-reading these pieces that her students were using their reflective essays to critique course curriculum as well as their own individual pieces of writing, she began to watch for patterns of suggestions in the essays. Thus, for example, if several kids voiced complaints about the same novel, Kathy would either select a different text for her next group or make changes in the way she was teaching that text. On the other hand, many positive evaluations imbedded within students' reflective essays reconfirmed their enthusiasm for a new instructional practice she had developed in conjunction with portfolio implementation and thereby convinced her to continue assigning frequent brief, informal freewrites. One student reaction supporting her use of these writing tasks within the literature instruction program read as follows: "The responses let me explore the thoughts in my head before turning them into a paper." Another echoed, "The little writing assignments were a good idea. Getting ideas down on paper even in very raw form is very beneficial to me."

Interestingly, however, there was less agreement about the kind and degree of directions Kathy should give in informal response assignments. One student, for instance, tried to encourage her to give more content-focused assignments ("I think there should have been more of them centered around the text" ). Another, on the other hand, preferred the chance to do personal writing for the informal pieces: "The assignments seemed to relate well with my life. For instance, the Ulysses response... tied in very well with my senioritis period. I like that, because it makes the papers easier and more fun to write." In this case, based on the variant student evaluations of her instructional strategies, Kathy decided to provide a varying mix of different kinds of writing as-

\section{At Central as at Valley, the introduction of a portfolio project stressing shared reflection in instruction and assessment has promoted ongoing evaluation of the classroom curriculum.}


signments in the next term, and, whenever feasible, to allow students options for writing either literary-analysis or "personal/creative" papers.

Reading reflective essays from Valley students as part of a curriculum-reforming dialogue has also led Kathy to increased use
Another of the most vital aspects of the Flint Portfolio Project's continued growth has been our own emphasis on cross-classroom and cross-school get-togethers of teachers involved in our program. of peer reading pairs, more opportunities to bring texts written for other classes or outof-school purposes into the portfolio revision process, and greater student input into the shaping of scoring rubrics, as well as the weighting of percentages for different portions of the overall portfolio grade. In fact, Kathy became so convinced of the value of having her students help with continuing redesign of her curriculum that she rewrote the directions for the reflective essay required in each portfolio so as to encourage her kids more explicitly to critique their learning and the class as well as their specific pieces of writing.

Early in the project, reflective essays in the portfolios for Kathy's classes were composed in response to a prompt focusing exclusively on student texts:

In your essay introducing your portfolio, please include the following:

- what you selected and why

- what you learned about writing these pieces and how

- improvements, strengths and weaknesses in your writing

- piece of writing that best represents your work and why

Now, however, the prompt reads differently, having added a call for students to "reflect on" the following, too:

- aspects of the class or particular assignments that were most helpful in working toward the improvement in your writing

- types of assignments that you would like to do more of

- assignments that you particularly disliked and why

\section{Bringing Parents into the Conversation}

At Central as at Valley, the introduction of a portfolio project stressing shared reflection in instruction and assessment has promoted ongoing evaluation of the classroom curriculum. But at the larger public high school, with its Humanities Magnet enrollment system drawing students from several other high schools all over the city, support for developing a classroom community from so many disparate elements has clearly needed to be an extra curricular goal. One of the techniques Susan and Jeanette developed to foster a more cohesive sense of community has been keyed to using portfolios to increase parent interest in and support of the overall English learning program.

In recent informal writing reflecting on her participation in the project, Jeanette singled out this parent involvement effort as one of the most crucial elements in her portfolio implementation approach and, ultimately, in the continued reforming of her several instructional programs.

Beginning the year with an "assignment" to a parent or any other significant adult for each student, Jeanette attempts to establish the idea that the curriculum in her classroom is collaboratively composed. For this introductory exercise, Jeanette asks each student to have an adult prepare an introduction of the student to the teacher. She asks that this reflective analysis include not only information about the personal background of the student but also some projected learning goals the student should set for the year. By involving parents in this kind of reflective, evaluative writing early in the year, Jeanette is modeling the way reflection enhances learning in her classroom and thus is helping parents better understand her use of this key instructional strategy by having them experience it first-hand.

But she is also opening up the curriculum-building conversation to include others often kept outside the classroom. By simultaneously inviting the parents to 1) share information about their children that might not normally find its way into classroom discourse and 2) try out the kind of readingand-writing to learn those children will be using, Jeanette invites both suggestions for constructive redesign of her curriculum to meet the needs of individual students and increased support of her portfolio program through improved parental understanding of its theories and practices. All in all, Jeanette's initial writing assignment for parents and the others that follow it throughout the year allow her curriculum an entryway into the home, and, at the same time, the texts the parents produce in response to their "prompt" suggest that, even early in the year, they are beginning to understand and support her instructional goals. Parents seem to enjoy responding to their assign- 
ment in a wide variety of creative ways, ranging from videos to letters to more traditional essays about their children.

\section{A NETWORK OF INTERTEXTUAL EXCHANGES: CROSS-SITE SHARING OF EMERGING CURRICULAR TEXTS}

Among the most important supports for our classroom research team's ongoing efforts to re-form curriculum have been parallel projects at other sites, which we often draw upon to enrich our own work. Colleagues at Henry Ford High School in Detroit, for instance, have been generous in sharing with us their experiences using portfolios. On a more formal institutional level, the University of Michigan's recent move to invite entering freshmen to submit portfolios of their writing has provided helpful affirmation of our classroom-level efforts to implement portfolio instruction and assessment programs. As Nancy Brandt observed in one of her recent reflective freewrites, we welcome such chances to share our students' work with post-secondary colleagues, especially since it provides those readers with "a real look at what our students read and write," a much clearer picture of "the breadth of a particular course ... than a mere title on a transcript."

Whether calling for portfolios as part of their admissions process or inviting them as an aid to placement in freshman composition courses, colleges can simultaneously assist classroom teachers' efforts to improve secondary composition instruction and learn more about incoming students' past reading and writing experiences. Thus, we believe, by becoming an audience for incoming students' portfolios, colleges can exercise their traditional power to shape high school curriculum-usually associated with standardizing and sometimes exclusionary forces like the SATs-in a more constructive way.

Another of the most vital aspects of the Flint Portfolio Project's continued growth has been our own emphasis on cross-classroom and cross-school get-togethers of teachers involved in our program. Most of these opportunities generally take the form of chatty after-school visits or extended phone conversations, and we have come to appreciate how crucial such informal, oral "curricular text-writing" can be, how such teacher talk can truly represent the most productive way to critique particular classroom practices and examine related conceptual questions. For us, this shared production of new teaching texts has been the most energizing way to expand our program to other classrooms as well.

At Valley, for example, the project has grown from Kathy's pilot classroom the first year to include students throughout the $\mathrm{K}$ 12 building who now carry forward a reading/writing portfolio each year. This portfolio can then be reviewed by kids and their new teachers every fall to help shape an individualized learning program based on their past work. And one key activity helping the students sense the possibilities for their growth as writers has been the crossage "Reading Our Writing" day in the spring, when upper schoolers and middlers visit their younger counterparts in the lower school, reading pieces from each others' portfolios in small groups, then reflecting together on the similarities and differences in their writing processes.

While the Valley version of our project has spread across its entire $\mathrm{K}-12$ spectrum, Central's portfolio implementation moved first into a few other classrooms in that building, then out into other sites within the Flint Community Schools system. District teachers who are trying out their own versions of the work begun in Susan's and Jeanette's classrooms meet regularly to exchange ideas. This kind of ongoing conversation about classroom-level curricular reform has also helped keep the teachers who have worked with the project from the beginning open to further refinement of their approaches. Cross-site discussions between Central and Valley, for instance, have led Nancy Brandt to try out Jeanette's "parent letters" at the smaller school, with equally compelling results. In addition, as we meet to plan workshops for other colleagues or to prepare essays like this one, we participants in the Flint Portfolio Project continue to be energized by the power of shared written reflections, and to be grateful for the ways in which this "intertextual" collaboration continues to help us "rewrite" the "texts" of our classroom curricula. 
Works Cited

Atwell, Nancie. 1987. In the Middle: Writing, Reading, and Learning with Adolescents. Portsmouth: Heinemann.

Atwell, Nancie. 1991. "Writing and Reading from the Inside Out." Literacy in Process. Eds. Brenda Miller Power and Ruth Hubbard. Portsmouth: Heinemann. 227-243.

Belanoff, Pat, and Marcia Dickson, eds. 1991. Portfolios: Process and Product. Portsmouth: Boynton/Cook, Heinemann.

Calkins, Lucy McCormick. 1986. The Art of Teaching Writing. Portsmouth: Heinemann.

"Frequently Asked Questions about the Standards Project." 1994. The Council Chronicle. 3.4: 4-5.

Hirsch, E. D., Jr. 1987. Cultural Literacy: What Every American Needs To Know. New York: Vintage.

Rief, Linda. 1991. Seeking Diversity: Language Arts with Adolescents. Portsmouth: Heinemann.
"Standards Project Seeks Wider Audience for Work to Date." 1994. The Council Chronicle. 3.4: 5 .

Sarah Robbins teaches at Kennesaw State College in Marietta, Georgia. She continues her collaboration with Nancy Brandt and Kathleen Wascha of the Valley School in Flint, Michigan, Susan Goering of Flint Community Schools, and Jeanette Nassif of Flint Central High School.

The five authors invite readers to join their discussions. Their addresses are:

Nancy Brandt and Kathy Wascha: The Valley School, 3301 N. Vernon, Flint, MI 48506

Jeanette Nassif: Flint Central High School, 601 Crapo, Flint, MI 48503

Susan Goering: Flint Community Schools, 923 E. Kearsley, Flint, MI 48503

Sarah Robbins: English Department, Kennesaw State College, P. O. 444, Marietta, GA 30061

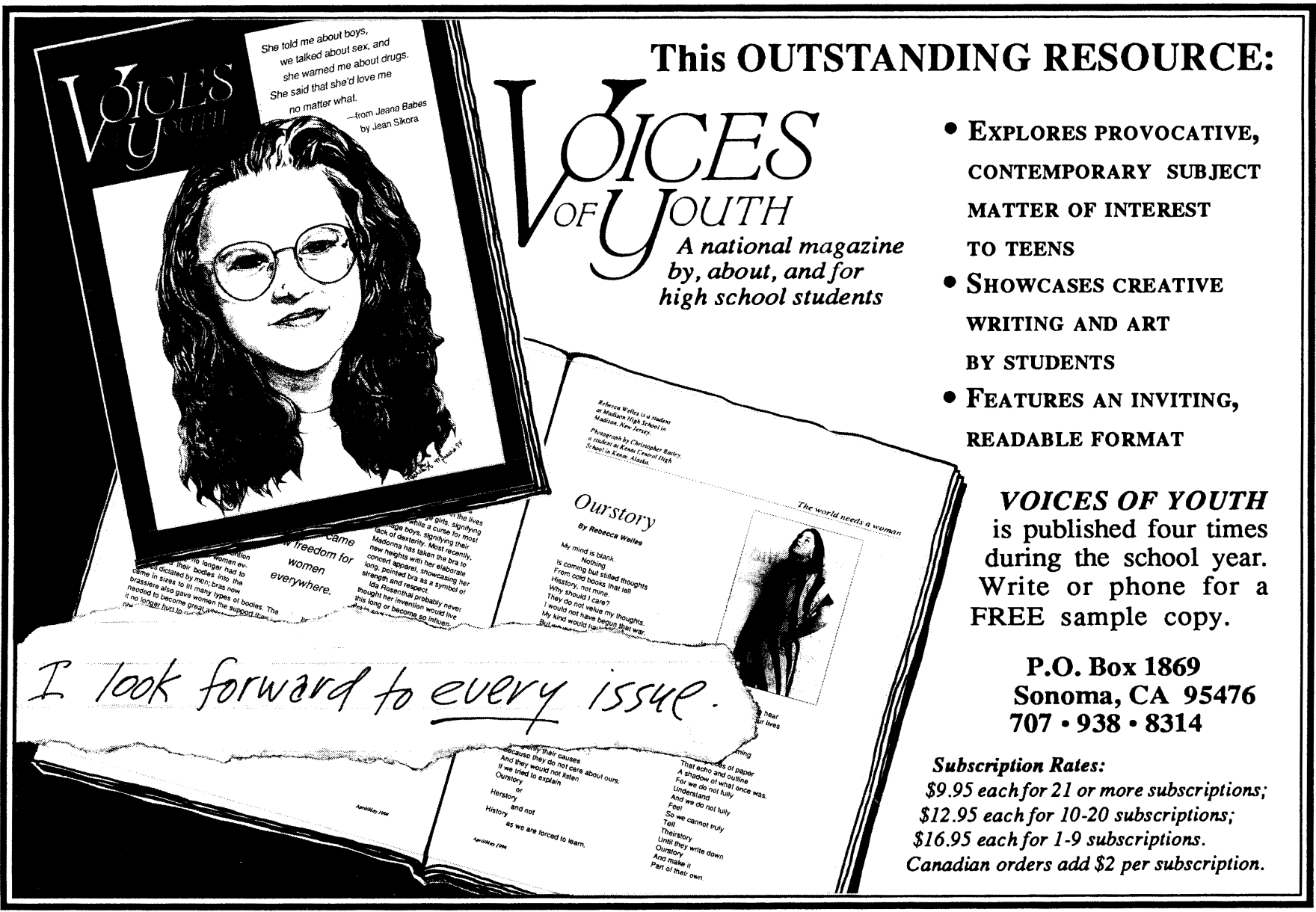


Ride With Me, Mariah Montana. Ivan Doig. 1991. New York: Penguin. 322 pp., \$10.00. ISBN 014-015607-0.

Finding regional literature that is well written and enjoyable is always a treat. Discovering Ivan Doig and his series of books about the early years of Montana was like find-

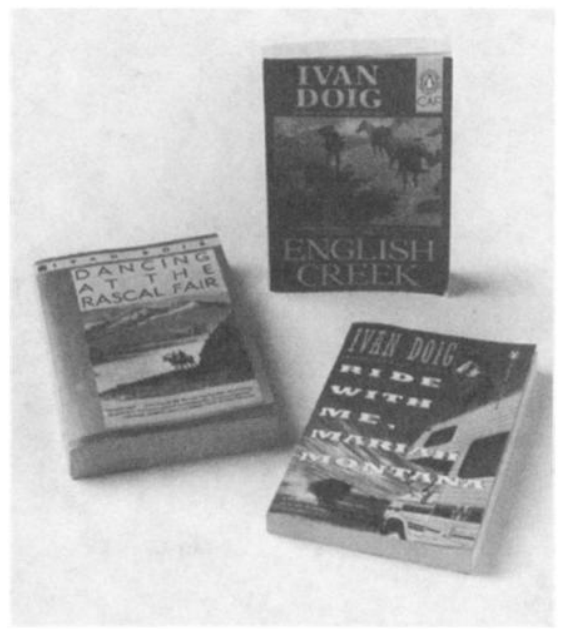

ing a grand present wrapped in the brightest of bows and ribbons. The series includes Dancing at the Rascal Fair, English Creek, and Ride With Me, Mariah Montana. I have read the first two, and they are terrific.

Dancing at the Rascal Fair, which covers the years 1889 to 1919 , begins the trilogy about the McCaskill family as Angus McCaskill and his best friend Rob Barclay emigrate from Scotland to the Two Medicine country of the Rocky Mountains. They find the adventure of their lives herding sheep, building homes, falling in love, raising families, and carving out their lives in the sometimes brutal environment of the rugged Montana territory. The two discover who they are as well as what the New World holds for them that is both happy and tragic. The reader learns of the need for immutable will in the relentless battle to survive the elements, as well as heartbreak and betrayal of life and love in northern Montana. The two main characters turn out to be as intractable as the land they are civilizing, and this richness in character is one of Doig's strengths. He tells a grand story where every character is real and every page is pleasure to read. Doig's style is strong and tender at the same time.

In English Creek, Jick McCaskill, son of Angus, relates the events of the summer of 1939 when he is "almost 15 and a half" and how these events change him and make him grow up. The initiating event is the announcement by his older brother Alec that he is going to be a cowboy on one of the most despised ranches in the area. This produces an immediate break with Jick's parents. The existence of one Leona, Alec's girl with "a sunburst smile" and who he plans to marry, rather than go on to college, brings further consternation and division to the family. Doig expertly captures the innocent age for Jick and, at the same time, for the U.S. just before World War II. By realizing his own connection to the land, Jick discovers himself and his own direction in life. Doig's writing is evocative, lyrical, and thoroughly enjoyable.

I recommend these books for their power, truth, adventure, and discovery. As historical regional novels, they are enlightening and instructive. As fiction, they are so well written that you have to actually concentrate on the page when you read-something not so necessary in contemporary fiction today. Take this journey with Ivan Doig, a National Book Award finalist. His writing is rich and rewarding.

\section{Gone Fishing}

Gregory D. Simpson

University of Alaska, Fairbanks

Ray Troll's Shocking Fish Tales: Fish, Romance, and Death in Pictures. Brad Matsen and Ray Troll, Illustrator. 1993. Berkeley, CA: Ten Speed Press. 101 pp., \$15.95. ISBN 0-89815-548-7.

This book, illustrated by Ketchikan, Alaska artist Ray Troll and written by Seattle-based author and editor Brad Matsen, is a fun-filled,

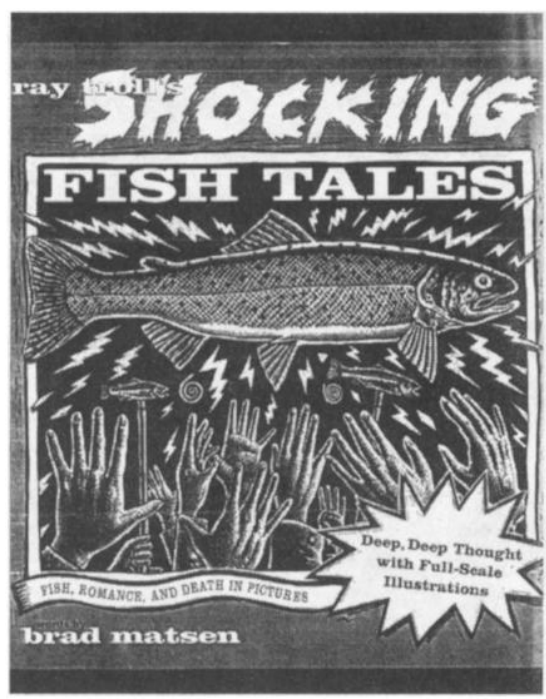

entertaining journey that weaves legend, natural history, narrative nonfiction and enviro-philosophical messages together with outrageous, original prints. This is a heavenly mixture of inter-disciplinary humor and seriousness, a book that I doubt I'll quote in any academic paper, but one I pick up over and over. It is a coffee table text that has coffee stains on the pages (not on the cover), a bedside companion that travels around the house, a book that captures the awe and joy of the unusual in the familiar, the surreal in the real, the usual in the absurd: a blender full of creative images and juxtapositions.

Fish Tales is a companion for any writer or reader who needs a fresh perspective. It illustrates the connections between marine biology, art, history, ethnography, and regional geography, and the blending of various writing and drawing techniques. As a gift, it is decidely less conventional than the standard Norman Rockwell or Georgia O'Keefe texts that end up on coffee tables and backroom shelves. 